\title{
STRATEGI PENGEMBANGAN MATA PENCAHARIAN ALTERNATIF UNTUK MENINGKATKAN PENDAPATAN RUMAH TANGGA NELAYAN DI PULAU KODINGARENG KOTA MAKASSAR
}

\author{
(Alternatif Livelihood Development Strategies To Increase the Income of Fishing \\ Households on the Kodingareng Island of Makassar)
}

\author{
oleh: \\ Nursanti 1), Syahrul 2), dan Andi Tamsil ${ }^{3)}$ \\ 1) PS. Manajemen Pesisir dan Teknologi Kelautan PPS UMI Makassar \\ ${ }^{2)}$ PS. Ilmu Kelautan FPIK-UMI \\ 3) PS. Studi Budidaya Perairan FPIK-UMI
}

Korespondensi: santiuchi@gmail.com

Diterima: tanggal 25 November 2018; Disetujui 31 November 2018

\begin{abstract}
This study aims to: (1) To indentify socio-economic characteristicsof fishing communities in Kodingareng island; (2) Formulate alternative livelihoodsto increase the income of fisherman households in kodingareng village; (3)Develop alternative livelihoodsto increase the income of fisherman households in kodingareng village of Makassar. The research was conducted on 01 September to 31 October 2018 on the Kodingareng Island of Makassar City. The method used in this study is: descriptive analysis, business feasibility analysis, and SWOT analysis. The results of the study indicate that alternative livelihoods that are feasible to develop are fiberglass manufacturing business, abon fish processing business, and fish cracker processing business. Suggestions and strategies that need to be considered include : (1) Conduct socialization, counseling and technical training in the hope that that the community, especially fisherman when not fishing, will continue to increase economic income but not conduct destructive activities; (2) Reactivate processing groups with guidance and supervision starting from raw material preparation, production, distribution, and marketing processes; (3) Need to get support and facilitation from the government, related to alterntive livelihoods that will be developed such as technical assistance and building business partnership patterns to obtain capital provision and broader market access.
\end{abstract}

Keywords: Alternative livelihoods, Kodingareng Islands, Income, And Househoolds

\begin{abstract}
ABSTRAK
Penelitian ini bertujuan: (1) untuk mengidentifikasi karakteristik social ekonomi masyarakat nelayan di Kelurahan Kodingareng; (2) merumuskan mata pencaharian alternative untuk meningkatkan pendapatan rumah tangga nelayan di Kelurahan Kodingareng; (3) Menyusun strategi pengembangan mata pencaharian alternative untuk meningkatkan pendapatan rumah tangga nelayan di Kelurahan Kodingareng Kota Makassar. Penelitian dilaksanakan pada 01September sampai 31 Oktober 2018 di Pulau Kodingareng Kota Makassar. Metode yang digunakan dalam penelitian ini adalah: analisis deskriktif, analisis kelayakan usaha, dan Analisis swot. Hasil penelitian menunjukkan mata pencaharian alternatif yang sangat layak dikembangkan adalah usaha pembuatan perahu fiber, usaha pengolahan abon ikan, dan usaha pengolahan kerupuk ikan. Saran dan strategi yang perlu diperhatikan antara lain: (1) Melakukan sosialiasi, penyuluhan dan pelatihan teknis usaha dengan harapan masyarakat terutama nelayan saat tidak melaut tetap meningkatkan pendapatan ekonomi namun tidak melakukan kegiatan destruktif; (2) Mengaktifkan kembali kelompok-kelompok pengolahan dengan bimbingan dan pengawasan mulai dari persiapan bahan baku, proses produksi, distribusi, hingga pemasaran; (3) Perlu mendapatkan dukungan dan fasilitasi dari pemerintah, terkait dengan mata pencaharian alternatif yang akan dikembangkan seperti pendampingan teknis dan membangun pola kemitraan bisnis untuk memperoleh penyediaan modal dan akses pasar yang lebih luas.
\end{abstract}


Kata Kunci: Mata Pencaharian Alternatif, Pulau Kodingareng, Pendapatan, dan Rumah Tangga

\section{PENDAHULUAN}

Potensi sumber daya alam Sulawesi Selatan, khususnya sumber daya alam laut merupakan potensi alami yang dapat memberikan kesempatan yang luas untuk membangun masyarakat dan daerah ini. Ketergantungan masyarakat pesisir dan pulau-pulau kecil yang sangat besar terhadap kualitas lingkungan hidup yang baik dan ketersediaan sumber daya alam mengharus-kan konservasi lingkungan menjadi bagian yang tak terpisahkan dalam perencanaan pengelolaannya. Besarnya potensi keanekaragaman hayati ekosistem di wilayah pesisir, laut, dan pulau-pulau kecil perlu mendapat perhatian serius dari pemerintah kota maupun badan legislatif dan stakeholders secara keseluruhan. Masyarakat nelayan dapat digolongkan sebagai penduduk yang terendah tingkat pendapatannya atau dikategorikan golongan penduduk miskin, dan pada umumnya mereka tinggal di daerah pesisir pantai.

Pulau Kodingareng Lompo merupakan bagian dari kelurahan Kodingareng Kecamatan Sangkarrang Kota Makassar. Penduduk pulau kodingareng menurut BPS 2013 tercatat 4.492 jiwa, jumlah kepala keluarga (KK) sebanyak 1043 KK. Sekitar 75\% penduduk pulau kodingareng menggantungkan diri sebagai nelayan tangkap (BPS 2013). Kegiatan menangkap ikan di laut merupakan suatu pilihan kegiatan yang di tekuni namun dapat dikatakan juga sebagai suatu kegiatan yang menjadi sandaran ekonomi keluarga. Namun kenyataannya kegiatan nelayan dalam menangkap ikan sangat dipengaruhi oleh cuaca dimana pada musim-musim tertentu teristimewa jika terjadi ombak yang besar karena angin kencang, memaksa nelayan tidak dapat melaut. Jika nelayan tidak dapat melaut maka untuk memenuhi kebutuhan sehari-hari mereka harus berusaha keluar dari kesulitan ekonomi dengan cara melibatkan semua anggota keluarga terutama ibu rumah tangga untuk ikut berkontribusi dalam menambah pendapatan rumah tangga (Monoton, 2006)

Rendahnya pendapatan masyarakat pulau, khususnya pulau kodingareng dipengaruhi oleh musim penangkapan ikan, kondisi alam, tingkat pendidikan yang masih rendah dan kendala ekonomi seperti terbatasnya modal sehingga usaha tidak berkembang, alat penangkapan ikan yang masih tradisional, transportasi kurang lancar, kelembagaan ekonomi tidak mendukung, dan posisi nelayan dalam penentuan harga hasil tangkapan sangat lemah. Hal ini mengakibatkan sebagian besar rumah tangga nelayan ekonominya lemah dan hidup pas-pasan atau miskin.

Pengembangan mata pencaharian alternatif (MPA) merupakan kebijakan pemerintah di bidang kelautan dan 
perikanan, merupakan penjabaran isi Undang-Undang RI Nomor 31 tahun 2004 tentang Perikanan, sedangkan kebijakan pengentasan kemiskinan merupakan penjabaran isi UndangUndang RI Nomor 11 tahun 2009 tentang Kesejahteraan Sosial.

Untuk meningkatkan pendapatan nelayan yang sekaligus meningkatkan kesejahteraan keluarganya dari satu sisi dan mengurangi eksploitasi sumberdaya perikanan serta degradasi habitatnya khususnya terumbu karang di sisi lainnya, harus dikembangkan mata pencaharian alternatif bagi nelayan. Namun untuk mengembangkan usaha alternatif tersebut memerlukan strategi mengingat dari satu sisi sangat tidak mudah untuk memulai sesuatu usaha yang baru bagi masyarakat nelayan yang tingkat ketergantungannya sangat tinggi terhadap sumberdaya perikanan, sedangkan disisi lain suatu usaha yang baru bisanya juga rentan untuk bertahan. Menentukan strategi pengembangannya berdasarkan pertimbangan faktor internal dan eksternalnya yang merupakan langkah konkrit yang perlu dilakukan disamping untuk mewujudkan usaha-usaha tersebut, juga berkaitan dengan keberlangsungan dan pengembangannya. Untuk itu perlu dilakukan suatu studi yang secara umum untuk mengetahui strategi pengembangan mata pencaharian alternatif di Kelurahan Kodingareng Kecamatan Sangkarrang Kota Makassar.

\section{MATERI DAN METODE}

Penelitian ini dilaksanakan pada bulan September-Oktober 2018 di Kelurahan Kodingareng Kecamatan Sangkarrang Kota Makassar.

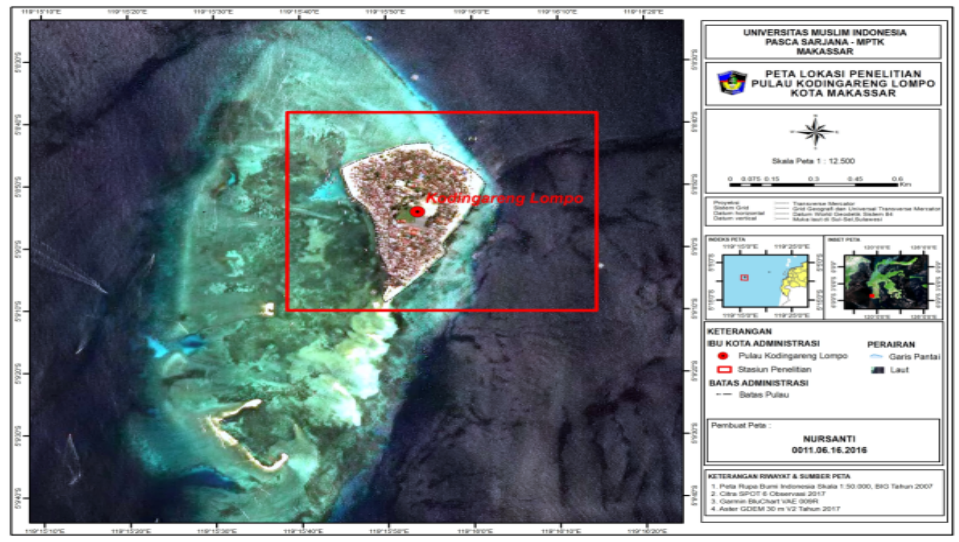

Gambar 1. Peta Lokasi Penelitian

Jenis data yang dikumpulkan rumusan masalah yang terjadi di dalam penelitian ini menggunakan data wilayah pulau Kodingareng. primer dan sekunder. Data primer Pengambilan data sekunder diperoleh meliputi karakteristik sosial ekonomi dari kantor Dinas Perikanan berupa nelayan tangkap di Kelurahan statistika perikanan, data kependudukan Kodingareng, data mata pencaharian dari kantor desa,kecamatan, Statistika, alternative masyarakat nelayan, data BAPPEDA dan lembaga lain yang 
terkait dengan penelitian ini, baik berupa pustaka, hasil penelitian maupun laporan.

Penelitian ini dilakukan dengan observasi langsung ke lapangan untuk mengetahui secara langsung mengenai berbagai hal yang berkaitan dengan nelayan di Pulau Kodingareng, wawancara mengenai aktifitas yang dilakukan Rumah Tangga Nelayan pada saat melakukan penelitian, penyebaran angket kuisioner kepada para responden, dalam hal ini adalah Rumah Tangga Nelayan Kodingareng. Dokumentasi dengan mengumpulkan berbagai informasi yang berhubungan dengan objek penelitian yang diperoleh dilapangan atau di laut.

Untuk memperoleh data yang dibutuhkan maka penentuan responden dilakukan secara acak sederhana (ramdom simple methode) dengan presisi $15 \%$ dengan formulasi sebagai berikut:

$$
\mathrm{n}=\frac{\mathrm{N}}{\mathrm{N} \cdot \mathrm{d}^{2}+1}
$$

Dimana :

$$
\begin{array}{ll}
\mathrm{N} & \text { :Sampel yang di cari } \\
\mathrm{N} & \text { :Jumlah populasi } \\
\mathrm{d}^{2} & \text { :Presisi yang ditetapkan }
\end{array}
$$

Analisis data dilakukan dalam 3 (tiga) tahap berurutan, yaitu i) analisis deskriktif terhadap data karakteristik nelayan. ii) Analisis kelayakan usaha untuk menentukan mata pencaharian alternative yang layak untuk dikembangkan. iii) Analisis swot untuk menentukan strategi pengembangan mata pencaharian alternative di Pulau Kodingareng kota Makassar
Untuk mendapatkan hasil penelitian yang cermat dan teliti dilakukan pendekatan studi secara bertahap. Tahap awal, mengenditifikasi karakteristik nelayan di wilayah pesisir Kelurahan Kodingareng, faktor-faktor yang diamati dan dilakukan evaluasi yang berhubungan dengan kegiatan pemanfaatan sumberdaya perikanan khususnya kegiatan nelayan perikanan tangkap. Data Karakteristik nelayan terdiri atas usia, tingkat pendidikan, jumlah tanggungan, alat tangkap yang digunakan, besarnya pendapatan dan komsumsi rumah tangga, dan mata pencaharian alternative.

Anlisis kelayakan usaha digunakan untuk mengetahui kelayakan usaha sehingga dapat merumuskan mata pencaharian alternative yang sesuai secara kriteria ekonomi. Analisis kelayakan usaha dari suatu kegiatan dapat dilakukan menggunakan $\mathrm{B} / \mathrm{C}$ Ratio (BCR), ROI dan PP (Kadariah et al., 1978). Analisis ini berguna untuk menghitung aspek ekonomi yang dapat diperoleh dari masing-masing usulan kegiatan mata pencaharian alternatif.

B/C Ratio dimaksudkan untuk mengetahui besarnya nilai perbandingan penerimaan dan biaya produksi yang digunakan. Rumus perhitungan ini seperti dikemukakan Hermanto (1998) adalah sebagai berikut:

$B / C$ Ratio $=\frac{\text { Total Penerimaan }}{\text { Total Biaya }}$

Kriteria yang digunakan adalah: $\mathrm{B} / \mathrm{C}$ ratio $>1$, berarti usaha menghasilkan keuntungan sehingga layak untuk dijalankan, $\mathrm{B} / \mathrm{C}$ ratio $=1$, 
berarti usaha tidak untung dan tidak rugi (impas), $\mathrm{B} / \mathrm{C}$ ratio $<1$, berarti usaha mengalami kerugian sehingga tidak layak untuk dijalankan.

PPC merupakan suatu metode dalam menilai kelayakan usaha yang digunakan untuk mengukur periode jangka waktu pengembalian modal (Maulana, 2008).

$$
\text { PPC }=\frac{T I}{N I} \times \text { Periode }
$$

Dimana :

TI : Pendapatan Bersih

$\mathrm{N} \quad$ : Total Investasi

Analisis SWOT adalah identifikasi berbagai faktor (Internal dan Eksternal) secara sistematis untuk merumuskan strategi pengembangan mata pencharian alternative untuk meningkatkan pendapatan rumah tangga nelayan di Pulau Kodingareng Kota Makassar. Menurut Rangkuti (2004), Analisis SWOT mempertimbangkan dua faktor secara umum, antara lain : faktor lingkungan internal (kekuatan dan kelemahan) serta lingkungan eksternal (peluang dan ancaman) yang dihadapi. Analisis SWOT membandingkan antara faktor eksternal peluang dan ancaman dengan faktor internal kekuatan dan kelemahan, sehingga dari analisis tersebut dapat diambil suatu keputusan strategi pengembangan.

\section{HASIL DAN PEMBAHASAN}

\author{
Kelurahan Kodingareng terletak \\ pada wilayah administrasi Kota \\ Makassar, Kecamatan Sangkarrang, \\ Kelurahan Kodingareng terdiri dari dua \\ pulau, yaitu Pulau Kodingareng yang
}

yang biasanya dinamakan oleh penduduk setempat sebagai Pulau Kodingareng Lompo, dan Pulau Kodingareng Keke.

Pulau

Kodingareng (Kodingareng Lompo) secara geografis terletak pada $119^{\circ} 16^{\prime} 00$ BT dan $05^{\circ} 08^{\prime} 54$ LS. Pulau Kodingareng memiliki luas $\pm 48 \mathrm{Ha}$ dan tinggi dari permukaan air laut 1,5 meter.

Usia/Umur merupakan indikator dalam pengukuran kemampuan fisik dan kesehatan mental spiritual untuk melakukan usaha, Johannes et al. (2000). Berdasarkan hasil wawancara, umur nelayan yang menjadi responden dalam penelitian ini berada pada kisaran yang termuda berusia $<20$ tahun sebanyak 2 orang, kisaran 20-26 tahun sebanyak 6 orang, 27-36 tahun sebanyak 11 orang,37-46 sebanyak 7 orang, 47-56 sebanyak 11 orang dan kisaran umur 57 66 tahun sebanyak 5 orang. Hal ini mengindikasi bahwa responden yang diwawancarai umumnya berada pada usia produktif, yang mana pada usia tersebut memiliki kemampuan fisik dan motivasi yang tinggi.

Pendidikan merupakan suatu hal yang sangat penting dalam mempengaruhi kualitas sumber daya manusia. Tingkat pendidikan berdasarkan tanggapan responden dengan jumlah 42 dapat dilihat pada tabel berikut :

Berdasarkan hasil wawancara terhadap responden bahwa tingkat pendidikan yang telah ditempuh oleh responden masih tergolong sangat 
rendah yaitu $71 \%$ tamat SD bahkan masih ada yang tidak tamat SD.

Tanggungan keluarga yang besar menurut Yamin (Hermanto 1995), bahwa faktor dominan yang mempengaruhi pengeluaran rumah tangga adalah tingkat pendidikan dan jumlah tanggungan keluarga. Berdasarkan hasil wawancara jumlah tanggungan responden terbesar pada kisaran 1-4 sebanyak 27 orang (64\%), menyusul kisaran 5-8 sebanyak 14 orang (33\%) bahkan ada responden yang jumlah tanggungan dalam keluarga berkisar 9-12 dalam satu keluarga yaitu sebanyak 1 orang (3\%) dari jumlah responden nelayan di pemukiman tersebut.

Produktivitas nelayan yang rendah umumnya diakibatkan oleh rendahnya keterampilan dan pengetahuan serta penggunaan alat penangkapan maupun perahu yang masih sederhana, sehingga efektivitas dan efisiensi alat tangkap belum optimal (Subani W dan HR Barus 1989). Berdasarkan hasil wawancara terhadap responden diketahui bahwa sebagian besar nelayan menggunakan alat tangkap yang masih sederhana yaitu sebanyak 28 responden menggunakan alat tangkap pancing, dan 14 menggunakan purse seine.

Pendapatan nelayan kelurahan Kodingareng beragam, secara pasti sangat sulit ditentukan karena hanya perkiraan responden. Namun dari hasil wawancara dapat diperkirakan besarnya pendapatan berkisar antara $<\mathrm{Rp}$. 1.500.000,- sampai > Rp. 3.000.000,per bulan. Pada dasarnya pendapatan nelayan berbeda setiap musimnya. Besarnya pendapatan per kapita dipengaruhi besarnya total pendapatan dan jumlah anggota keluarga dalam rumah tangga.

\section{Merumuskan Mata Pencaharian alternative}

Untuk mengetahui layak atau tidaknya sebuah usaha untuk dikembangkan perlu dilakukan analisis kelayakan usaha. Hasil analisa kelayakan usaha pengolahan abon Ikan dapat dilihat pada tabel 18 berikut:

Tabel 18. Hasil analisis kelayakan usaha pengolahan abon ikan

\begin{tabular}{cll}
\hline No. & \multicolumn{1}{c}{ Uraian } & \multicolumn{1}{c}{ Nilai } \\
\hline 1 & Penerimaan satu kali produksi & Rp. 13.500 .000 \\
2 & Pendapatan bersih satu kali produksi & Rp. 4.089.000 \\
3 & Total biaya & Rp. 9.411 .000 \\
4 & Biaya Investasi & Rp. 4.075 .000 \\
5 & B/C Ratio & 1,4 \\
6 & PCC & 0,9 \\
\hline
\end{tabular}

Berdasarkan hasil analisis kelayakan yang dilakukan terhadap usaha pengolahan abon ikan, didapatkan nilai BCR yaitu sebesar 1,4 yang artinya setiap pengeluaran Rp. 1 diperoleh keuntungan 1,4 sehingga jika $B / C$ Ratio memiliki nilai lebih dari satu $(B / C$ Ratio $>$ 1) dimana usaha tersebut layak untuk dilanjutkan (Yulinda, 2012). Nilai PPC 0,9 tahun yang artinya pengembalian 
modal selama 10,8 bulan, semakin rendah nilai PPC maka semakin cepat pengembalian modal (Hendrik, 2010).

Analisa Kelayakan Usaha Pembuatan Perahu Fiberglass
Hasil analisa kelayakan usaha pembuatan perahu fiber diperoleh nilai sebesar 1,4 artinya setiap mengeluarkan sebesar Rp. 1 diperoleh hasil sebesar Rp. 1,4. Untuk selengkapnya dapat dilihat pada tabel berikut:

Tabel 19. Hasil analisis kelayakan usaha pembuatan perahu fiberglass

\begin{tabular}{clr}
\hline No. & \multicolumn{1}{c}{ Uraian } & Nilai \\
\hline 1 & Penerimaan satu kali produksi & 7.000 .000 \\
2 & Pendapatan bersih satu kali produksi & 2.089 .000 \\
3 & Total biaya & 4.911 .000 \\
4 & Biaya Investasi & 1.590 .000 \\
5 & B/C Ratio & 1,4 \\
6 & PCC & 0,6 \\
\hline
\end{tabular}

Berdasarkan hasil analisis kelayakan yang dilakukan terhadap usaha pembuatan perahu fiberglass, didapatkan nilai BCR yaitu sebesar 1,4 yang artinya setiap pengeluaran Rp. 1 diperoleh keuntungan 1,4 sehingga jika B/C Ratio memiliki nilai lebih dari satu
$(B / C$ Ratio $>1)$ dimana usaha tersebut layak untuk dilanjutkan (Yulinda, 2012). Nilai PPC 0,6 yang artinya pengembalian modal selama 7,2 bulan, semakin rendah nilai PPC maka semakin cepat pengembalian modal (Hendrik, 2010).

\section{Analisa Kelayakan Usaha}

\section{Pengolahan Kerupuk ikan}

Hasil analisa kelayakan usaha mengeluarkan uang sebesar Rp.1 kerupuk ikan, nilai kalayakan usaha BC mendapatkan hasil Rp. 1,2 dapat dilihat ratio 1,2 yang berarti setiap pada tabel 20 berikut:

Tabel 20. Hasil analisis kelayakan usaha pengolahan kerupuk ikan

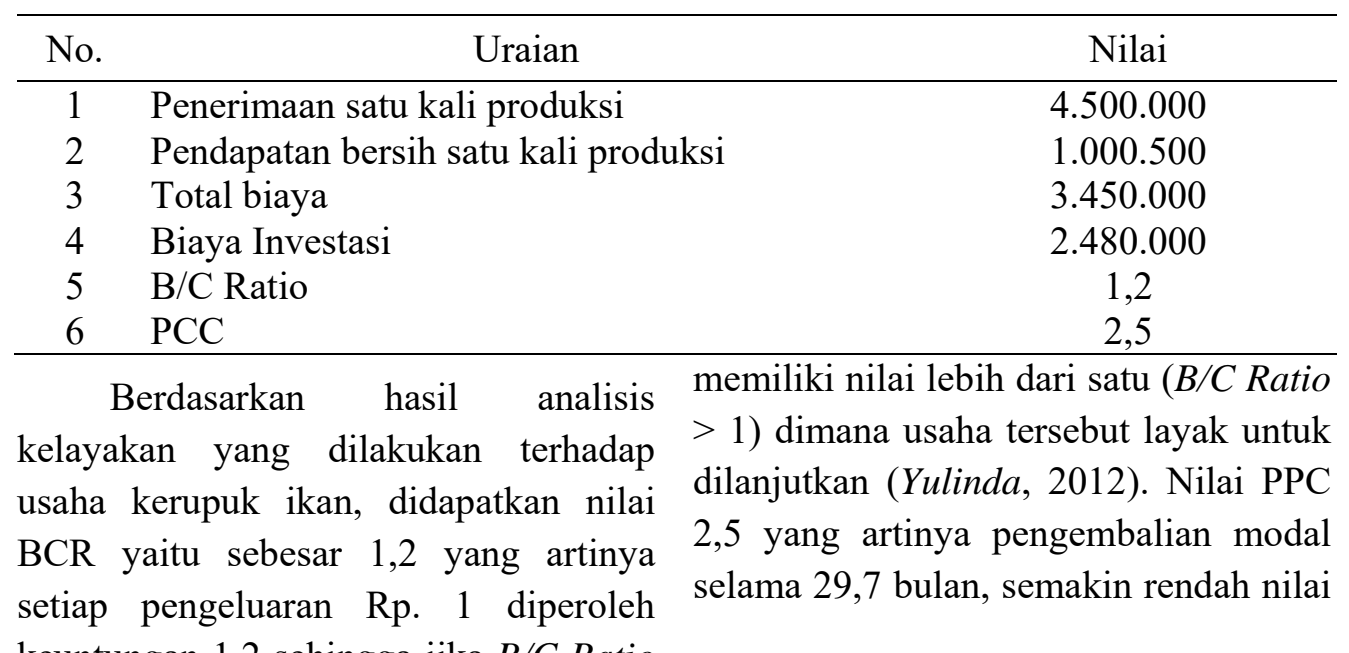
keuntungan 1,2 sehingga jika $B / C$ Ratio 
PPC maka semakin cepat pengembalian modal (Hendrik, 2010).

Penentuan mata pencaharian alternatif di Kelurahan Kodingareng setelah melakukan analisis finansial atau analisis kelayakan usaha mata pencaharian alternative nelayan, hasil analisis kelayakan usaha memberikan rekomendasi mata pencaharian alternative yang layak untuk dikembangkan yaitu prioritas pertama adalah usaha pembuatan perahu fiber, prioritas kedua adalah pengolahan abon ikan, dan prioritas ketiga adalah home industry kerupuk ikan.

\section{Strategi Pengembangan}

Pencaharian Alternatif

Menentukan pengembangan mata pencaharian alternative untuk meningkatkan pendapatan rumah tangga nelayan di Pulau kodingareng menggunakan Analisis SWOT (Strength, Weakness, Opportunity, and Threats). Tahapan analisis SWOT yang digunakan dalam menganalisis data lebih lanjut yaitu mengumpulkan semua informasi yang mempengaruhi pengembangan mata pencaharian alternatif pada wilayah kajian, baik secara eksternal maupun secara internal. Hasil studi lapangan melalui analisis data primer dan sekunder yang dilakukan berdasarkan metodologi penelitian.

Unsur kekuatan (strength) antara lain potensi SD perikanan, potensi SD, dan pendapatan dari usaha perikanan tangkap. Adapun unsure kelemahan (Weakness) antara lain rendahnya pendidikan nelayan, keterbatasan modal, keterbatasan keterampilan, akses pasar, dan tidak berfungsinya kelompok-kelompok pengolahan hasil perikanan. Unsur peluang (opportunity) antara lain dukungan pemerintah daerah, dukungan dan partisipasi masyarakat, dan program bantuan pemerintah Sedangkan unsur ancaman (threat) antara lain persaingan pasar, musim dan cuaca buruk, dan nilai-nilai dan kebiasaan masyarakat nelayan dalam melakukan kegiatan ekonomi.

Prioritas Strategi Pengembangan Mata Pencaharian Alternatif berdasarkan hasil analisis yang dilakukan terhadap factor internal 'dan eksternal, ditetapkan 8 strategi Terbaik pengembangan Mata Pencaharian Alternatif Untuk Meningkatkan Pendapatan Rumah Tangga Nelayan di Pulau Kodingareng Kota Makassar antara lain sebagai berikut: 1). Pengelolaan kawasan SD Perikanan secara optimal dengan melibatkan semua stakeholder, 2). Meningkatkan kualitas potensi SDM (masyarakat nelayan) agar mampu memanfaatkan SD perikanan \& laut secara optimal, 3) Pengembangan MPA untuk meningkatkan pendapatan selain dari hasil tangkapan, 4) Memberikan bimbingan dan dampingan melalui sosialisasi dan penyuluhan dalam hal peningkatan kapasitas, pengetahuan, dan keterampilan masyarakat dalam usaha mata pencaharian alternative, 5) Mengaktifkan fungsi kelembagaan sosial yang ada pada masyarakat nelayan, 6) Pengadaan koperasi simpan pinjam untuk mengatasi kesulitan modal, 7)Pendekatan social budaya sebelum kegiatan MPA diluncurkan untuk merubah cara pandang 
masyarakat mengenai kegiatan untuk menambah pendapatan rumah tangga secara berkelompok, 8) Membangun pola kemitraan bisnis yang memungkinkan memperoleh akses modal untuk meningkatkan produksi dan akses pemasaran untuk meningkatkan permintaan terhadap produk dari kegiatan MPA.

\section{KESIMPULAN}

Berdasarkan uraian hasil penelitian, pembahasan yang diperoleh dari lapangan dan hasil analisa, dapat disimpulkan beberapa uraian untuk menjawab rumusan masalah sebagai berikut:

1. Karakteristik nelayan di Kelurahan Kodingareng Kota Makassar adalah: Umur/usia nelayan berada pada usia produktif yaitu berkisar antara 20-57 tahun, Tingkat pendidikan nelayan sangat rendah yaitu sebanyak 30 responden (71\%) hanya tamatan Sekolah dasar (SD), Jenis alat tangkap yang digunakan nelayan yaitu $64 \%$ alat tangkap pancing dan 34\% alat tangkap purse seine, Pendapatan rumah tangga nelayan tidak tetap dan sangat dipengaruhi oleh musim, cuaca, dan alat tangkap yang digunakan. Adapun konsumsi rumah tangga nelayan relative sama tergantung dari banyaknya tanggungan keluarga.

2. Mata pencaharian alternative nelayan di Kelurahan Kodingareng yang layak dikembangkan adalah usaha pembuatan perahu fiber, usaha pengolahan abon ikan, dan usaha pengolahan Kerupuk ikan
3. Strategi yang diperlukan dalam upaya pengembangan mata pencaharian alternative untuk meningkatkan pendapatan rumah tangga nelayan diKelurahan Kodingareng Kota Makassar adalah: (1) Sosialiasi, penyuluhan dan pelatihan teknis usaha mata pencaharian alternatif. Mengaktifkan kembali kelompokkelompok pengolahan dengan bimbingan dan pengawasan mulai dari persiapan bahan baku, proses produksi, distribusi, hingga pemasaran, (3) Perlu mendapatkan dukungan dan fasilitasi dari pemerintah, terkait dengan mata pencaharian alternatif yang akan dikembangkan .

\section{SARAN}

1. Pengembangan mata pencaharian alternatif untuk meningkatkan pendapatan rumah tangga nelayan harus didukung oleh kebijakan pemerintah melalui fasilitas modal usaha dan tekhnologi, sehingga peranan mata pencaharian alternative dalam meningkatkan pendapatan rumah tangga nelayan di Kelurahan Kodingareng dapat lebih ditingkatkan.

2. Perlu dilakukan penelitian lanjutan mengenai kontribusi mata pencaharian alternative terhadap pendapatan rumah tangga nelayan di Kelurahan Kodingareng Kota Makassar.

\section{UCAPAN TERIMA KASIH}

Penulis mengucapkan terima kasih kepada Pemerintah Kota Makassar 
dalam hal ini Lurah Pulau Kodingareng yang telah memberikan izin, kerjsama dan dukungan dalam pengumpulan datadata penelitan, demikian juga perusahaan perusahaan lokasi penelitian hingga selesai serta para pembimbing dan para reviewer yang telah banyak memberikan masukan dan komentar untuk memperbaiki tulisan ini.

\section{DAFTAR PUSTAKA}

BPS. 2013. Kecamatan Ujung Tanah dalam angka. Badan Pusat Statistik Kota Makassar. Makassar.

BPS. 2015. Kecamatan Ujung Tanah dalam angka. Badan Pusat Statistik Kota Makassar. Makassar.

Hendrik. 2010. Analisis Usaha dan Potensi Pengembangan Keramba Jaring Apung di Desa Sikakap Kabupaten Kepulauan Mentawai Sumatera Barat. Universitas Riau. Jurnal Pertanian-Unri. Vol 37, No 1 (2010).

Hernanto F. 1995. Ilmu Usaha Tani. Jakarta : Penebar Swadaya. 309 hal.
Johannes RE, Freeman MMR, Hamilton RJ. 2000. Ignore fishers' knowledge and miss the boat. Fish and Fisheries. 1:257-271.

Kadariah, L. K. \& C. Gray. 1978. Pengantar Evaluasi Proyek. Penerbit : Fakultas Ekonomi Universitas Indonesia. Jakarta.

[KKP] Kementerian Kelautan dan Perikanan Republik Indonesia. 2014. Kelautan dan Perikanan dalam Angka . [Internet]. [diunduh $18 \quad$ Maret 2014].http://statistik.kkp.go.id/.

Rangkuti F. 2014. Analisis SWOT Teknik Membelah Kasus Bisnis. Jakarta (ID): PT Gramedia Pustaka Utama.

Subani W dan HR Barus. 1989. Alat Penangkapan Ikan dan Udang Laut Indonesia. Nomor 50 tahun 1988/1989 Edisi Khusus. Jurnal Penelitian.

Yulinda, E. 2012. Analisis Finansial Unsur Pembenihan Ikan Lele Dumbo (Clarios Geriepius) Kelurahan Lembah Sari Kecamatan Rumbai Pesisir Kota Pekanbaru Riau. Universitas Riau. Jurnal Perikanan dan Kelautan. 